\title{
Diagnostic Usefulness of p16 Immunohistochemistry for some Epithelial Lesions in the Pathology Service of Sultan Qaboos University Hospital
}

Iman AL-GHAFRI, Samia AL-HUSSEINI, Afrah AL-RASHDI, Mohammad ARAFA

Pathology Department, College of Medicine and Health Sciences, Sultan Qaboos University, Oman

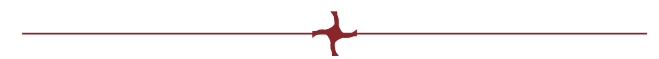

\begin{abstract}
Objectives: This study is aiming to assess the diagnostic value of p16 immunohistochemistry (IHC) for a variety of epithelial lesions in the service provided by the Department of Pathology at Sultan Qaboos University Hospital (SQUH), Sultanate of Oman. This study would enhance pathologists' ability to diagnose and differentiate between different types of epithelial lesions reliably.

Methods: This study is a retrospective observational cross-sectional study. A total of 117 immunohistochemical tests for $p 16$ were collected from the pathology lab at SQUH from January 2010 to December 2020. Data was analyzed using SPSS software. For numerical data, mean and percentages were used. For measuring the association between different pathological and clinical findings, the categorized variables were analyzed using the chi-square test.

Results: Immunohistochemistry of p16 was mainly used to diagnose uterine cervical, ovarian, oropharyngeal and anal epithelial lesions. Predominately, it was applied on cervical intraepithelial neoplasia grades 1, 2 and 3 (CIN I, II, III), squamous metaplasia, chronic cervicitis, anal intraepithelial neoplasia as well as different types of squamous cell carcinoma, adenocarcinoma, and serous carcinoma.

Conclusions: The results of the present study revealed the wide application of $p 16$ IHC as a marker to reach the final histopathological diagnosis of epithelial lesions in the pathology lab at SQUH. The marker can be used effectively to differentiate between different types of lesions showing similar appearance on hematoxylin and eosin stain.
\end{abstract}

Keywords: immunohistochemistry, p16, epithelial lesions, human papilloma virus.

\footnotetext{
Address for correspondence:

Dr. Mohammad Arafa, Associate Professor

Department of Pathology, College of Medicine and Health Sciences, Sultan Qaboos University, Sultanate of Oman

Tel: (+968) 2414 1123; email: marafa@squ.edu.om
}

Article received on the $20^{\text {th }}$ of September 2021 and accepted for publication on the $16^{\text {th }}$ of December 2021 


\section{INTRODUCTION}

I mmunohistochemistry (IHC) is an important supportive tool in the pathology service worldwide. It helps in reaching the accurate histopathological diagnosis, and in some situations, in planning treatment and predicting prognosis. It precisely helps in visualizing the distribution and quantity of a certain molecule using antigen-antibody reaction (1). The unique aspect that makes IHC stand out among many other laboratory experiments is that it is conducted without the destruction of histological architecture and thus allows evaluation of the molecule's expression pattern in the histological context (1).

One of the commonly used IHC markers is p16. Antibodies against p16 are important for the evaluation of a variety of pathological lesions, mainly human papilloma virus (HPV) related epithelial lesions (2).

p16 is a tumor suppressor gene and is known as INK4a (inhibitor of cyclin-dependent kinase 4a), p16INK4, CDKN2A (cycline-dependent kinase inhibitor 2A) and MTS-1 (major tumor suppressor 1). The INK4 family comprises four members, including p16INK4A, p15INK4B, p18INK4C and p19INK4D, exhibiting similar biological features involved in inhibiting cell growth and suppressing tumors $(3,4)$. The tumor suppressor gene p16 encodes proteins involved in controlling a fundamental cell cycle pathway, which is the retinoblastoma $(\mathrm{Rb})$ pathway. The p16 protein binds to cycline-dependent kinases 4 and 6 and maintains the retinoblastoma gene product $(\mathrm{Rb})$ in its hypophosphorylated state (active state), which in turn binds to the transcription factor $\mathrm{E} 2 \mathrm{~F}$ and prevents the progression of the cell cycle and so, in turn, it prevents the transformation of the cell into a tumor cell $(3,4)$.

In high risk HPV-related lesions such as cervical, anal, vulvar, perineal, vaginal and penile squamous lesions, virus integration into the host cell genome results in the release of viral oncoproteins E6 and E7 (5); E6 will cause degradation of p53 and $\mathrm{E} 7$ causes inactivation of $\mathrm{Rb}$, resulting in the release of the transcription factor E2F and progression of the cell cycle. Consequently, there will be an increased expression of p16 as a negative feedback control that can be identified by IHC in both the nucleus and cytoplasm of the affected cells, indicating that the cell is undergoing abnormal changes $(5,6)$.

However, studies have shown that p16 was also expressed by HPV-independent pathways in many tumors, such as Hodgkin and non-Hodgkin lymphomas, gastric adenocarcinomas, pulmonary adenocarcinomas, liposarcomas, neuroendocrine carcinomas and a subset of uterine carcinomas (5). The Rb inactivation due to point mutations, gene deletion, functional mutations, or other mechanisms of deregulation of the $\mathrm{Rb}$ pathway explains the p16 overexpression in these tumors (5). On the other hand, other nonHPV-related tumors such as colon, breast, pancreas carcinomas, melanomas and smoking-related carcinomas of the head and neck, cause gene deletions and mutations in p16, resulting in the loss of its role (5).

The use of p16 immunostaining in the lower anogenital tract and oropharynx tumors is the most commonly studied, accepted, and practiced use (2). The Lower Anogenital Squamous Terminology Standardization Project for HPVAssociated Lesions (LAST Project) suggested guidelines for the use of p16 immunostaining; p16 was chosen as the preferred biomarker for the histopathological diagnosis of cervical lesions (7). They recommended the use of p16 IHC in four situations: a) to distinguish high-grade squamous intraepithelial lesion (HSIL) from mimics like atrophy and immature squamous metaplasia; b) in the diagnosis of cervical intraepithelial neoplasia grade 2 (CIN2), which morphologically falls between a low-grade and higher grade preinvasive lesions; $\mathrm{c}$ ) in the case of professional dispute; and d) in high-risk colposcopic referral circumstances (7).

In the current study, the diagnostic usefulness of p16 IHC in the pathology service provided by SQUH was further evaluated. This will mainly encompass certain surface epithelial malignancies, their precursor lesions, and mimics.

\section{MATERIALS AND METHODS}

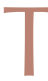
his study was conducted in the Pathology Department of Sultan Qaboos University Hospital (SQUH) in Muscat, Sultanate of Oman. The present study was a retrospective observational (cross-sectional study). It included all p16 IHC performed in the pathology lab at SQUH from January 2010 to December 2020. 
Data from a total of 323 patients was collected. We excluded any p16 IHC used in patients with non-epithelial types of lesions, patients with missing data of p16 IHC in their pathology report and p16 IHC done for patients from outside SQUH. After exclusion criteria, only 117 patients remained. Patients' data was retrieved from the medical record system (TrackCare) at SQUH hospital information system (HIS) and included medical record identification (MRI), year, age, gender, type of biopsy, site of the lesion, histopathological diagnosis, p16 IHC result and HPV IHC result. Patients' data was inserted manually into the statistical package for the social sciences (SPSS) software.

Data was analyzed using SPSS software. For numerical data, mean and percentages were used. For measuring the association between different pathological and clinical findings, the categorized variables were analyzed using the chi-square test and P-value of .05 or less was taken as significant.

The IHC results were reported as one of two patterns of expression. The first pattern is overexpression (abnormal expression) showing diffuse nucleo-cytoplasmic strong staining. The other pattern is negative to patchy pattern showing focal nuclear or cytoplasmic weak staining.

Ethical approval was obtained on September 2020 by the Medical \& Research Ethics Committee (MREC) at the College of Medicine and Health Sciences (CoMHS), Sultan Qaboos University, Muscat, Sultanate of Oman (MREC\# 2262).

\section{RESULTS}

istribution of $p 16$ tests in relation to gender and anatomical location

The current study investigated data of 117 tests of p16 IHC that were collected from January 2010 to December 2020 after applying the exclusion criteria to assess the usage of p16 IHC in the pathology lab of SQUH. There were 101 females, accounting for $86.3 \%$ of the total sample, and only $16(13.7 \%)$ males. The median age of the whole group sample was 56 (23-90) years. Patients were represented with a wide variety of lesions including cervical, ovarian, uterine, vaginal, labial, anal, pharyngeal, laryngeal, bladder, oral, breast, skin, lung, hepatic, prostatic, and urethral lesions. Most of the cases were females
TABLE 1. Distribution of p16 tests in relation to gender and anatomical location

\begin{tabular}{|c|c|c|c|}
\hline & Males & Females & Total \\
\hline Number of cases & $16(13.7 \%)$ & $101(86.3 \%)$ & $117(100 \%)$ \\
\hline Median age & $61(24-82)$ years & $55(23-90)$ years & $56(23-90)$ years \\
\hline $\begin{array}{l}\text { Percentage of } \\
\text { performed tests in } \\
\text { relation to gender } \\
\text { and anatomical } \\
\text { location }\end{array}$ & $\begin{array}{l}31.3 \% \text { anal lesions } \\
18.8 \% \text { pharyngeal lesions } \\
18.8 \% \text { laryngeal lesions } \\
12.5 \% \text { oral lesions } \\
6.3 \% \text { lung lesions } \\
6.3 \% \text { prostatic lesions } \\
6.3 \% \text { urethral lesions }\end{array}$ & $\begin{array}{l}61.4 \% \text { cervical lesions } \\
11.9 \% \text { ovarian lesions } \\
10.9 \% \text { uterine lesions } \\
4 \% \text { bladder lesions } \\
3 \% \text { vaginal lesions } \\
2 \% \text { breast lesions } \\
2 \% \text { anal lesions } \\
1 \% \text { pharyngeal lesions } \\
1 \% \text { skin lesions } \\
1 \% \text { oral lesions } \\
1 \% \text { labial lesions } \\
1 \% \text { liver lesions }\end{array}$ & $\begin{array}{l}53 \% \text { cervical lesions } \\
10.3 \% \text { ovarian lesions } \\
9.4 \% \text { uterine lesions } \\
6 \% \text { anal lesions } \\
3.4 \% \text { pharyngeal lesions } \\
3.4 \% \text { bladder lesions } \\
2.6 \% \text { laryngeal lesions } \\
2.6 \% \text { oral lesions } \\
2.6 \% \text { vaginal lesions } \\
1.7 \% \text { breast lesions } \\
0.9 \% \text { skin lesions } \\
0.9 \% \text { labial lesions } \\
0.9 \% \text { lung lesions } \\
0.9 \% \text { hepatic lesions } \\
0.9 \% \text { prostatic lesions } \\
0.9 \% \text { urethral lesions }\end{array}$ \\
\hline
\end{tabular}




\begin{tabular}{|c|c|c|c|c|c|c|}
\hline & \multicolumn{3}{|c|}{ HPV-IHC results } & \multirow[b]{2}{*}{ Total } & \multirow[b]{2}{*}{$P$ value } \\
\hline & & Positive & Negative & $\begin{array}{l}\text { Not } \\
\text { performed }\end{array}$ & & \\
\hline \multirow[t]{2}{*}{$\begin{array}{l}\text { p16 IHC } \\
\text { results }\end{array}$} & $\begin{array}{l}\text { Overexpressed } \\
\text { (abnormal) }\end{array}$ & $17(77.3 \%)$ & $8(19 \%)$ & $36(67.9 \%)$ & $61(52.1 \%)$ & \multirow[t]{3}{*}{$\mathrm{P}<0.0005$} \\
\hline & $\begin{array}{l}\text { Patchy to } \\
\text { negative }\end{array}$ & $5(22.7 \%)$ & $34(81 \%)$ & $17(32.1 \%)$ & $56(47.9 \%)$ & \\
\hline \multicolumn{2}{|l|}{ Total } & $22(100 \%)$ & $42(100 \%)$ & $53(100 \%)$ & $117(100 \%)$ & \\
\hline
\end{tabular}

TABLE 2.

Association between p16 IHC results and HPV-IHC results with cervical lesions (53\%). Males represented mostly with anal, oropharyngeal, and laryngeal lesions (Table 1).

\section{Prevalence of p16 IHC usage}

For calculating the prevalence, all p16 IHC were included without excluding any case and they were a total of 323 tests. p16 IHC usage was variable over the past 10 years (2010-2020). Its utilization was fluctuating to reach the maximum number of cases in 2016, 2017, 2018 with 54, 53 , and 52 tests respectively. The lowest number was in 2010 with only eight tests.

In the pathology lab at SQUH, $212 \mathrm{IHC}$ markers are routinely used. Over the past 10 years (2010-2020), 149808 tests were done, of which 16888 in 2015. Among these markers, p16 IHC usage accounted for $0.2 \%$ of the total number of tests.

\section{Association between p16 IHC results and HPV IHC results}

Human papilloma virus immunohistochemistry was studied to prove the association between HPV infection and p16 expression at the cellular level. Chi-square test was used to assess the relationship between them, and the $p$-value was less than 0.05 , indicating a significant relationship between these two variables. Table 2 is showing that in HPV-positive patients, p16 has been mostly showing overexpressed positive stain (77.3\%). On the other hand, non-infected patients were mostly showing patchy to negative p16 IHC results (81\%).

\section{Diagnostic usefulness of p16 IHC in epithelial lesions}

In this study, p16 IHC was used in the diagnostic workup of about 37 different types of epithelial lesions (Table 3). The lesions were mainly of lower anogenital and gynaecological types. The test was predominantly used to confirm the diagnosis of cervical intraepithelial neoplasia (CIN). In the present study, CIN lesions were grade 1 ( CIN I, also known as low-grade intraepithelial lesion "LSIL"), grade 2 and grade 3 (CIN II and CIN III, also collectively known as high-grade intraepithelial lesion "HSIL"). Other cervical benign non-dysplastic lesions submitted for the test included squamous metaplasia, chronic cervicitis, atrophy, and polyps. Other gynaecological lesions such as vaginal intraepithelial neoplasia

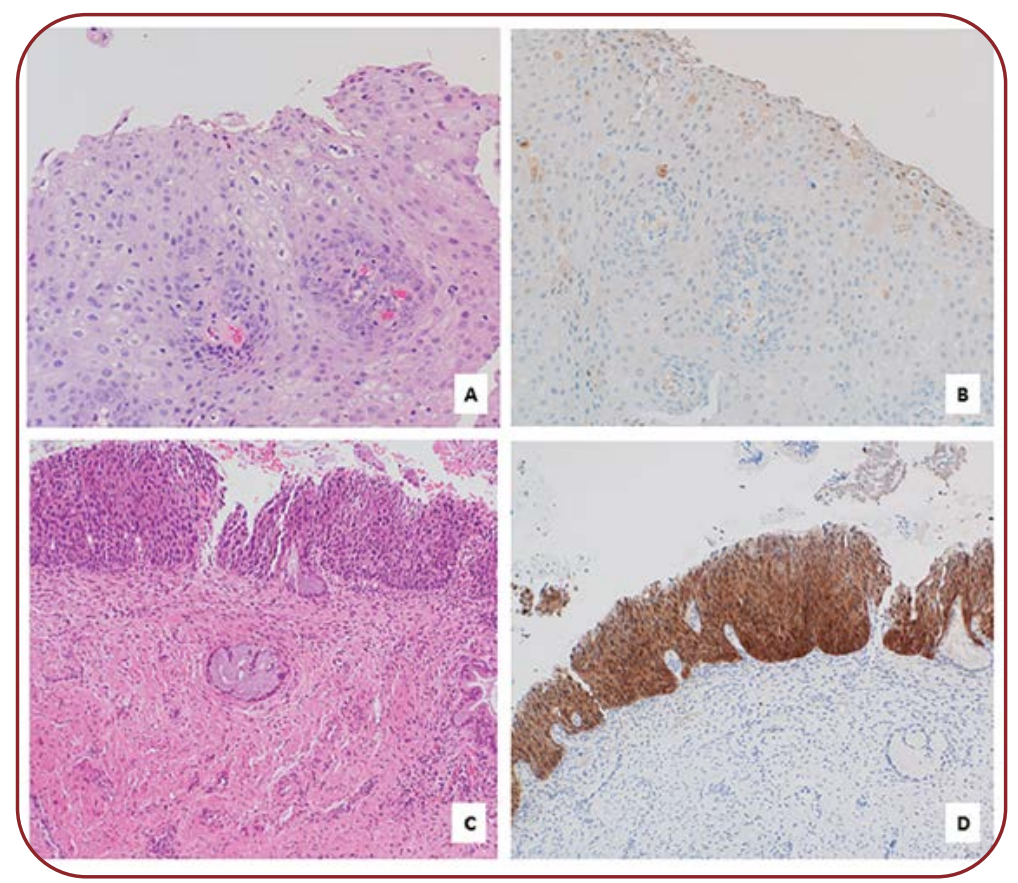

FIGURE 1. Examples of lesions with expression patterns of p16 immunohistochemistry in cervical biopsies. Low-grade intraepithelial lesion H\&E stained section (A), shows faint scattered p16 cells by IHC (B). High-grade intraepithelial lesion H\&E stained section (C), shows abnormal overexpression pattern in the form of intense diffuse nucleo-cytoplasmic p16 staining by IHC (D) 


\begin{tabular}{|c|c|c|c|}
\hline \multirow[b]{2}{*}{ The type of the epithelial lesion } & \multicolumn{2}{|l|}{ p16 result } & \multirow[b]{2}{*}{ Total } \\
\hline & $\begin{array}{l}\text { Overexpressed } \\
\text { (abnormal) }\end{array}$ & $\begin{array}{l}\text { Patchy to } \\
\text { negative }\end{array}$ & \\
\hline CIN I & 4 & 6 & 10 \\
\hline CIN II & 8 & 1 & 9 \\
\hline CIN III & 7 & 1 & 8 \\
\hline Koilocytosis & 0 & 3 & 3 \\
\hline Cervical squamous cell carcinoma & 7 & 2 & 9 \\
\hline Cervical adenocarcinoma & 8 & 1 & 9 \\
\hline Cervical carcinosarcoma & 0 & 1 & 1 \\
\hline Chronic cervicitis & 0 & 4 & 4 \\
\hline Endocervical polyp & 0 & 2 & 2 \\
\hline Cervical atrophic changes & 0 & 1 & 1 \\
\hline Cervical squamous metaplasia & 0 & 9 & 9 \\
\hline $\begin{array}{l}\text { Endometrial endometrioid } \\
\text { carcinoma }\end{array}$ & 1 & 4 & 5 \\
\hline Endometrial serous carcinoma & 2 & 0 & 2 \\
\hline Endometrial clear cell carcinoma & 0 & 1 & 1 \\
\hline $\begin{array}{l}\text { Ovarian serous carcinoma } \\
\text { (ovarian biopsy) }\end{array}$ & 5 & 4 & 9 \\
\hline $\begin{array}{l}\text { Ovarian serous carcinoma } \\
\text { (peritoneal deposits) }\end{array}$ & 3 & 0 & 3 \\
\hline Vaginal intraepithelial neoplasia & 0 & 1 & 1 \\
\hline Vaginal Squamous hyperplasia & 0 & 1 & 1 \\
\hline Vaginal adenocarcinoma & 1 & 1 & 2 \\
\hline Labial squamous cell carcinoma & 0 & 1 & 1 \\
\hline $\begin{array}{l}\text { Oropharyngeal squamous cell } \\
\text { carcinoma }\end{array}$ & 1 & 4 & 5 \\
\hline Oropharyngeal adenocarcinoma & 0 & 1 & 1 \\
\hline Oral leukoplakia & 0 & 1 & 1 \\
\hline Pharyngeal Schneiderian papilloma & 1 & 0 & 1 \\
\hline Anal intraepithelial neoplasia & 3 & 1 & 4 \\
\hline Anal squamous cell carcinoma & 2 & 1 & 3 \\
\hline Hepatic neuroendocrine carcinoma & 2 & 0 & 2 \\
\hline Lung squamous cell carcinoma & 0 & 1 & 1 \\
\hline Breast metaplastic carcinoma & 0 & 1 & 1 \\
\hline $\begin{array}{l}\text { Poorly differentiated breast } \\
\text { carcinoma }\end{array}$ & 0 & 1 & 1 \\
\hline Bladder adenocarcinoma & 0 & 1 & 1 \\
\hline Urothelial carcinoma & 0 & 1 & 1 \\
\hline
\end{tabular}

TABLE 3. Patterns of p16 IHC results among different types of epithelial lesions 
Continued from previous page

\begin{tabular}{|l|l|l|l|}
\hline Bladder squamous cell carcinoma & 0 & 1 & 1 \\
\hline Cystitis & 0 & 1 & 1 \\
\hline Urethral condyloma acuminate & 0 & 1 & 1 \\
\hline Prostatic squamous cell papilloma & 0 & 1 & 1 \\
\hline Skin papillomatosis & 1 & 0 & 1 \\
\hline Total & $\mathbf{5 5}$ & $\mathbf{6 1}$ & $\mathbf{1 1 7}$ \\
\hline
\end{tabular}

and different types of invasive carcinomas, including squamous cell carcinoma, adenocarcinoma, and certain ovarian and endometrial carcinomas, have been tested too. Other types of epithelial lesions included anal intraepithelial neoplasia and oropharyngeal carcinomas. Examples of the expression patterns of p16 by immunohistochemistry are illustrated in Figure 1.

\section{DISCUSSION}

$\mathrm{T}$ his research work was conducted to assess the usage of p16 IHC and exploring the different pattern of its utilization in a variety of epithelial lesions. To our knowledge, this was the first study done in Oman related to this field of research.

Over a period of 10 years, p16 testing accounted for $0.2 \%$ of all tests utilizing $212 \mathrm{IHC}$ markers in the pathology lab at SQUH. There was variation in the total number of p16 IHC tests done over these years, with the highest number being recorded in 2016 .

Our findings showed that p16 expression by IHC was tightly correlated with HPV infection. Abnormal overexpression (positive) with diffuse block type nucleo-cytopamic staining pattern was mostly seen in HPV-positive patients. On the other hand, patchy weak to absent (negative) staining was detected in HPV-negative patients. Therefore, we have also found that p16 was widely used in females presented with lower anogenital, gynaecological and oropharyngeal/ head and neck lesions, many of which were known to be HPV related (2). The widest application was on cervical intraepithelial neoplasia grades 1,2 and 3 ( $\mathrm{CIN} \mathrm{I}, \mathrm{II}, \mathrm{III})$ and squamous metaplasia. This application is correlating with the recommendations mentioned in the LAST guidelines for the usage of p16 in high and lowgrade squamous intraepithelial lesions (LSIL and $\mathrm{HSIL}$ ) and differentiating them from their mim- ics, such as metaplasia (7). The marker expression in these lesions was variable, were CIN I (LSIL) and squamous metaplasia were mostly showing patchy to negative stain, while CIN II and III (HSIL) showed an abnormal overexpression (2). Therefore, a distinction can be made between them using p16 as recommended in the LAST guidelines (7). Other cervical lesions have been also tested, including chronic cervicitis, cervical atrophic changes, endocervical polyp, koilocytosis, cervical squamous cell carcinoma, adenocarcinoma and cervical carcinosarcoma. In those lesion, p16 IHC was positive in malignant cases such as cervical adenocarcinoma and squamous cell carcinoma, while atrophy, chronic cervicitis, koilocytosis and endocervical polyp were negative. These findings were confirmed by other previous studies too (8-10). The marker p16 has also been used in lesions rather than the uterine cervix. Ovarian, endometrial, vaginal, labial, anal and oropharyngeal related lesions were also tested. Its utilization in the ovary was in ovarian serous carcinoma and in their disseminated peritoneal diseases, for which it was showing intense diffuse positive staining, despite being known to be HPV independent lesions (8). Additionally, it was used in endometrial endometrioid adenocarcinoma, serous carcinoma, clear cell carcinoma. Its expression was changeable between positive in serous cell carcinoma (8) and negative in clear cell carcinoma (11). Remarkably, it was showing patchy stain in endometrial endometrioid adenocarcinoma and this finding can be applied to differentiate between endometrial and cervical adenocarcinoma that are showing similar appearance on $\mathrm{H} \& \mathrm{E}$ stain, where the cervical one is mostly positive $(6,12)$. Other gynaecological application included vaginal intraepithelial neoplasia where p16 IHC was unexpectedly negative, whereas vaginal adenocarcinoma showed an overexpres- 
sion of the marker (13). On the other hand, labial squamous cell carcinoma was negative (14). Moreover, it was used in anal intraepithelial and anal squamous cell carcinoma, where both of them were positive, in concordance with previous works $(15,16)$. Furthermore, our results showed that it can be applied in patients with oropharyngeal squamous cell carcinoma, where its cellular expression was predominantly patchy to negative stain, indicating that these lesions where mostly HPV independent (17).

Immunostaining for p16 was further applied on minor types of lesions that were represented in our series. It was used in the diagnostic workup of two patients presented with hepatic neuroendocrine carcinoma and it was positive in both cases. These results are conflicting with a previous Japanese study that have shown a negative expression for the marker (18). Another usage was in one patient with lung squamous cell carcinoma showing patchy stain (19). Two other female patients had breast metaplastic carcinoma and poorly differentiated carcinoma negative p16 staining, in agreement with a South Korean study (20). In addition, p16 IHC was used in a variety of urinary system related lesions, including bladder urothelial carcinoma, adenocarcinoma and squamous cell carcinoma, cystitis and urethral condyloma acuminate. All of them were showing patchy stain, as reported previously (21). We found similar results to those previously reported for isolated cases of prostatic squamous cell papilloma (22), pharyngeal Schneiderian papilloma (23), oral leukoplakia (24) and skin papillomatosis (25).

Since the current research is single-cantered, the utility of p16 immunohistochemistry may be underestimated due to selection bias and the relatively small sample size. Despite the long period covered by this study, many of the lesion entities were presented relatively in a small number of patients. This is partly because many tests were performed for referral material where the stained slides were sent back for interpretation to the requesting pathologist. Moreover, interpretation of p16 IHC staining in SQUH was not included in some of the pathology reports.

Efforts should be emphasized on the importance of using p16 in the histopathological diagnosis of certain epithelial lesions. This includes expanding its usage in the pathology lab at different hospitals. This study could expand to collaborate with other health centres to obtain more reliable data about the usage of this marker in different pathology labs in the country. In addition, further studies should be done to investigate its utility in non-epithelial lesions. Finally, we encourage pathologists to document their interpretation of any IHC test they requested in the pathology report.

\section{CONCLUSION}

To conclude, the results of the present study revealed an appropriate application of p16 IHC as a diagnostic marker to reach the final histopathological diagnosis of certain epithelial lesions in the pathology lab of SQUH. The majority of cases with p16 diagnostic usefulness are the HPV related lesions. This was mainly encompassing uterine cervical, gynecologic and oropharyngeal epithelial lesions. It is recommended be used to differentiate between different types of lesions showing similar appearance on $\mathrm{H} \& \mathrm{E}$ stained tissue sections. The settings of its usage were comparable with previous studies, reflecting our proper use of the marker.

Conflicts of interest: none declared.

Financial support: none declared.

\section{R}

1. Schacht V, Kern JS. Basics of immunohistochemistry. J Invest Dermatol 2015;135:1-4.

2. Mahajan A. Practical issues in the application of p16 immunohistochemistry in diagnostic pathology. Hum Pathol 2016;51:64-74.

3. Serrano M. The tumor suppressor protein p16INK4a.
Exp Cell Res 1997;237:7-13.

4. Kim WY, Sharpless NE. The regulation of INK4/ARF in cancer and aging. Cell 2006;127:265-275.

5. Iaconis L, Hyjek E, Ellenson LH, Pirog EC. p16 and Ki-67 immunostaining in atypical immature squamous metaplasia of the uterine cervix: correlation with human papillomavirus detection.
Arch Pathol Lab Med 2007;131:1343-1349.

6. Arafa M, Boniver J, Delvenne P. Detection of HPV-induced cervical (pre) neoplastic lesions: a tissue microarray (TMA) study. Appl Immunohistochem Mol Morphol 2008;16:422-432.

7. Clinton LK, Miyazaki K, Ayabe A, et al. The LAST guidelines in clinical 
practice: implementing recommendations for p16 use. Am J Clin Pathol 2015;144:844-849.

8. O'Neill CJ, McCluggage WG. p16 expression in the female genital tract and its value in diagnosis. Adv Anat Pathol 2006;13:8-15.

9. Krishnappa P, Mohamad IB, Lin YJ, Barua A. Expression of P16 in high-risk human papillomavirus related lesions of the uterine cervix in a government hospital, Malaysia. Diagn Pathol 2014;9:202.

10. Lim S, Lee MJ, Cho I, et al. Efficacy of p16 and Ki-67 immunostaining in the detection of squamous intraepithelial lesions in a high-risk HPV group. Oncol Lett 2016;11:1447-1452.

11. Yoon G, Koh CW, Yoon N, et al. Stromal p16 expression is significantly increased in endometrial carcinoma. Oncotarget 2017;8:4826-4836.

12. McCluggage WG, Jenkins $D$. p16 immunoreactivity may assist in the distinction between endometrial and endocervical adenocarcinoma. Int J Gynecol Pathol 2003;22:231-235.

13. Bertoli HK, Rasmussen CL, Sand FL, et al. Human papillomavirus and p16 in squamous cell carcinoma and intraepithelial neoplasia of the vagina. Int J Cancer 2019;145:78-86.
14. Dong F, Kojiro S, Borger DR, et al. Squamous Cell Carcinoma of the Vulva: A Subclassification of 97 Cases by Clinicopathologic, Immunohistochemical, and Molecular Features (p16, p53, and EGFR). Am J Surg Pathol 2015;39:1045-1053.

15. Albuquerque A, Rios E, Dias CC, Nathan M. p16 immunostaining in histological grading of anal squamous intraepithelial lesions: a systematic review and meta-analysis. Mod Pathol 2018;31:1026-1035.

16. Ju JY, Stelow EB. Clinicopathologic Features of Anal and Perianal Squamous Cell Carcinomas and Their Relationship to Human Papillomavirus. Am I Surg Pathol 2019;43:827-834.

17. Lewis JS Jr. p16 immunohistochemistry as a standalone test for risk stratification in oropharyngeal squamous cell carcinoma. Head Neck Pathol 2012;6 Suppl 1(Suppl 1):S75-82.

18. Matsuda $Y$, Ichida $T$, Matsuzawa J, et al. p16(INK4) is inactivated by extensive CpG methylation in human hepatocellular carcinoma. Gastroenterology 1999;116:394-400.

19. Wang CW, Wu TI, Yu CT, et al. Usefulness of p16 for differentiating primary pulmonary squamous cell carcinoma from cervical squamous cell carcinoma metastatic to the lung. Am J Clin Pathol 2009;131:715-722.
20. Shin E, Jung WH, Koo JS. Expression of p16 and pRB in invasive breast cancer. Int J Clin Exp Pathol 2015;8:8209-8217.

21. Alexander RE, Hu Y, Kum JB, et al. p16 expression is not associated with human papillomavirus in urinary bladder squamous cell carcinoma. Mod Pathol 2012;25:1526-1533.

22. Remo A, Pancione M, Zanella C, Manfrin E. p16 Expression in Prostate Cancer and Nonmalignant Lesions: Novel Findings and Review of the Literature. Appl Immunohistochem Mol Morphol 2016;24:201-206.

23. Lin GC, Scheel A, Akkina S, et al. Epidermal growth factor receptor, p16, cyclin D1, and p53 staining patterns for inverted papilloma. Int Forum Allergy Rhinol 2013;3:885-889.

24. Prakash $P$, Khandare M, Kumar M, et al. Immunohistochemical Detection of p16(INK4a) in Leukoplakia and Oral Squamous Cell Carcinoma. J Clin Diagn Res 2013;7:2793-2795.

25. Švajdler M Jr, Mezencev R, Kašpírková J, et al. Human papillomavirus infection and $\mathrm{p} 16$ expression in the immunocompetent patients with extragenital/extraungual Bowen's disease. Diagn Pathol 2016;11:53. 